\title{
Prevalence and Determinants of Modifiable Risk Factors for Chronic Non-Communicable Diseases among Adults in Mizan-Aman Town, Ethiopia: A Community Based Cross Sectional Study
}

\author{
Teklemariam Ergat Yarinbab ${ }^{1 *}$ and Fessahaye Alemseged ${ }^{2}$ \\ ${ }^{1}$ Department of Public Health, College of Health Sciences, Mizan-Tepi University, Mizan-Aman, Ethiopia \\ ${ }^{2}$ Department of Epidemiology, College of Health Sciences, Jimma University, Jimma, Ethiopia
}

Submission: June 02, 2018; Published: June 13, 2018

*Corresponding author: Teklemariam Ergat Yarinbab, Department of Public Health, College of Health Sciences, Mizan-Tepi University, MizanAman, Ethiopia, Email:teklemariam36@gmail.com

\begin{abstract}
Background: Chronic non-communicable diseases impose a large burden on human health worldwide. Even though the burden of these chronic non-communicable diseases in Ethiopia is increasing significantly; their prevalence across different regions of the country is not known clearly. Likewise, there has been no research conducted in Mizan-Aman town on the prevalence of risk factors of chronic non-communicable diseases. Therefore, the aim of this study was to assess prevalence and determinants of modifiable risk factors for chronic non-communicable diseases among adults in Mizan-Aman town, Ethiopia.
\end{abstract}

Methods: A cross-sectional study was conducted in Mizan-Aman town, Ethiopia. Systematic random sampling technique was used. Data analysis was done by SPSS for Windows Version 20.0. Binary and multivariable logistic regressions were conducted. P-value $<0.05$ was used to declare statistically significant variables.

Results: From behavioral risk factors, the prevalence of smoking is $8.4 \%, 35.9 \%$ for alcohol consumption, $23.3 \%$ for consumption of fruits and vegetables below adequate level, $10.6 \%$ for low level of total physical activity and $14.1 \%$ for khat chewing. The prevalence of biological risk factors, on the other hand, is $12.1 \%$ for hypertension, $12.1 \%$ for overweight, $4.0 \%$ for obesity and $21.29 \%$ for central obesity. Physical inactivity was associated with educational status $(\mathrm{AOR}=5.02,95 \% \mathrm{CI}=1.40,17.95)$ whereas hypertension was associated with age $(\mathrm{AOR}=2.16,95 \% \mathrm{CI}=$ $1.13,4.12)$ and work status (AOR=3.86, $95 \% \mathrm{CI}=1.97,7.52)$. Moreover; overweight showed a significant association with sex $(\mathrm{AOR}=4.89,95 \% \mathrm{CI}=$ $2.63,9.08)$ and age $(\mathrm{AOR}=2.31,95 \% \mathrm{CI}=1.23,4.35)$.

Conclusion: Above half of the study population had at least one or more of the key risk factors of chronic non-communicable diseases. Sex, age, educational status, marital status, work status and income were positive predictors of risk factors of CNCDs. Besides; current alcohol drinking, low servings of fruits and/or vegetables and physical inactivity showed a significant association with biological risk factors of CNCDs.

Keywords: Prevalence; Cncds; Modifiable Risk Factors; Mizan-Aman Town; Ethiopia

\section{Background}

Chronic non-communicable diseases (CNCDs) impose a large burden on human health worldwide; and are the major causes of mortality and morbidity. CNCDs were responsible for $68 \%$ of the 56 million deaths that occurred in 2012. The burden of chronic diseases, especially in developing countries, is increasing rapidly and is becoming a significant social, economic, and health consequences [1]. The increasing incidence of chronic diseases in low-income countries of Sub-Saharan Africa (SSA) poses a growing challenge to their national health systems, [2] given that infectious diseases are still highly prevalent in these settings. The increase is attributed to interrelated changes in demographic and socio-economic determinants, influenced by globalization
$[3,4]$. A reviewed literature on non-communicable diseases (NCDs) in SSA showed that the prevalence of stroke ranged from 0.07 to $0.3 \%$, diabetes mellitus from 0 to $16 \%$, hypertension 6 to $48 \%$ and current smoking from 0.4 to $71 \%$ [2]. World Health Organization (WHO) estimated in 2011 that 34\% of Ethiopian population is dying from non-communicable diseases, with a national cardiovascular disease prevalence of $15 \%$, cancer and chronic obstructive pulmonary disease prevalence of $4 \%$ each, and diabetes mellitus prevalence of $2 \%$ [5].

These troublesome CNCDs are caused by different modifiable risk factors. The major modifiable risk factors are classified in to two major categories namely behavioral risk factors and 
biological risk factors. The behavioral risk factors include physical inactivity, unhealthy diet, tobacco use, and harmful alcohol consumption whereas the biological risk factors include high blood cholesterol, high blood pressure, and overweight/ obesity. Regular and repeated intake of Khat, also, has recently been reported to be associated with increased risk of high blood pressure [6,7]. Behavioral risk factors: The global prevalence of tobacco use/smoking is $21 \%$ whereas its prevalence in SSA, Kenya and Nigeria were $40 \%, 9 \%$ and $4.7 \%$ respectively [810]. Likewise, findings from a community based cross-sectional study in Ethiopia revealed that the prevalence of smoking was 9.3\% [11]. The global prevalence of harmful alcohol use, on the other hand, is reported to be $38.3 \%$ whilst its prevalence as revealed from studies in Uganda and Ethiopia were 19.9\% and $7.1 \%$ respectively [9,12]. A study on 1978 subjects in Mekong Delta showed that only $24.3 \%$ had $\geq 5$ servings of fruits and/or vegetables per day [13]. Similarly, a study in Ethiopia revealed that $27 \%$ of the study population ate less than five servings of fruit and/or vegetables per day [11]. The findings of studies in Kenya and Tanzania, on the other hand, revealed that the prevalence of physical inactivity were $42 \%$ \& $21.1 \%$, respectively $[9,14]$. A study in South West Ethiopia showed that the prevalence of Khat chewing was $38.6 \%$ [11].

Biological risk factors: The global prevalence of hypertension and overweight among adults, as reported by WHO, were $40 \%$ and $35 \%$, respectively. Findings from studies in North-West Iran and Mekong Delta, Vietnam, showed that the prevalence of hypertension were $18 \%$ and $30.4 \%$, respectively $[13,14]$. Another study in Ethiopia revealed that $9.3 \%$ of the study participants were hypertensive. A study in Northern Nigeria, on the other hand, revealed that the prevalence of overweight were $53.3 \%$ and $11 \%$ [10]. On the contrary, a study in Ethiopia revealed that the prevalence of overweight among men and women were $5.7 \%$ and $7.2 \%$, respectively [15].

These findings might imply that the distribution of risk factors of CNCDs is widespread across different areas of the world. This may be basically due to the differences in socio-demographic and lifestyle circumstances of these different regions/countries. But the prevalence of risk factors of CNCDs in Mizan-Aman town was not yet known. Therefore, the objective of this study was to assess prevalence and determinants of modifiable risk factors of CNCDs in Mizan-Aman town, SNNPRS, Ethiopia.

\section{Methods}

\section{Study Area and Period}

The study was conducted in Mizan-Aman town from October 10-30/2015. The town is the capital and administrative center of Bench Maji zone; located 561 KMs South West of Addis Ababa; the capital city of the country. Mizan-Aman town has a latitude and longitude of $700^{\prime} \mathrm{N} 35035^{\prime} \mathrm{E} / 7.0000 \mathrm{~N} 35.5830 \mathrm{E}$ and an elevation of 1451 meters. It has an estimated total population of 49,591(projected from national census) and 10,331 households. It is also subdivided in to five kebeles' (the smallest governmental administrative units) namely Edget, Kometa, Addis Ketema, Hibret and Shesheka; with the population of 11156, 7921, 11937, 8784, \& 9793, respectively. The town has two governmental health institutions, 20 private clinics and 15 private drug stores.

\section{Study Design}

A community based cross sectional study was conducted. All individuals' aged 25-64 years and lived in the town at least for six months were eligible participants for the study. Pregnant women and persons' who were critically sick were excluded from the study.

\section{Sample Size Determination and Sampling Procedure}

Sample Size Determination: To estimate the sample size; a formula for single population proportion was used. The sample size was calculated by taking the estimated average khat chewing $38.6 \%$ (11). Five percent margin of errors with $95 \%$ confidence of certainty of any outcome was used (where $n$ is desired sample size, $\mathrm{Z}$ is the value of standard normal variable at $95 \%$ confidence interval, and $\mathrm{P}$ is the proportion of Khat chewer which is $38.6 \%$ ). Therefore, with the $10 \%$ contingency for non respondents the final sample size became 404 .

Sampling Procedure: Systematic random sampling technique was used. Samples were taken from all the five Kebeles' found in the town. First, the sample size was proportionally allocated to each kebele; according to the number of households they possessed. Next, the interval to select the households for data collection was determined to be $\approx 25$. Then; after the first household $(\mathrm{HH})$ was selected by lottery method among the first coming $25 \mathrm{HHs}$, every $25^{\text {th }}$ households were included in the study by systematic random sampling technique. Only one participant was taken from a household. Whenever, the number of eligible individuals within a selected household was more than one, a participant had been selected by lottery method. When household members did not fulfill the inclusion criteria the next household had been taken and so on. This process continued by taking an eligible participant from every $25^{\text {th }}$ household, until the sample size allocated for each kebele was satisfied.

\section{Operational Definitions}

Modifiable Risk Factors: are unhealthy diet, physical inactivity, smoking, khat chewing, harmful use of alcohol, hypertension and overweight.

Low Serving of Fruits and/ or Vegetables: is serving of fruits and/or vegetables $<5 /$ day.

One Standard Alcoholic Drink: is a certain amount of alcoholic drink contains 10 gm of ethanol.

Heavy Drinker: For men $\geq 5$ standard drinks per day and for women $\geq 4$ standard drinks per day 
Physical Inactivity: mean a total physical activity $<600$ MET-minutes/week.

Hypertension: Systolic blood pressure (BP) $\geq 140 \mathrm{mmHg}$ or Diastolic BP $\geq 90 \mathrm{mmHg}$ and/or currently on antihypertensive medication.

Overweight: study participants with Body Mass Index (BMI) $25-29.9 \mathrm{Kg} / \mathrm{m}^{2}$.

General Obesity: study participants with BMI $\geq 30 \mathrm{~kg} / \mathrm{m}^{2}$.

Central Obesity: denotes WHR $>1.0$ for men and WHR > 0.85 for women.

\section{Data Collection Tool and Procedure}

The data was collected using structured interviewer administered questionnaires adapted from WHO STEP-wise approach for CNCDs surveillance, prepared in English and translated in to local language(Amharic) and vice versa. Fifteen senior diploma nurses (data collectors) and two senior public health professionals (supervisors) were recruited and participated in the data collection. Training was given to data collectors and supervisors on the details of the instruments, data collection processes, communication and supervisory roles based on the WHO STEPS surveillance manual. Then, sociodemographic and behavioral risk factors data were collected through structured interviewer administered questionnaires. Next, the physical measurements were conducted using the tape meter, digital automatic BP apparatus, weight scales and height scales immediately after the behavioral measurements; in the order of Blood pressure, Height, Weight, waist circumference, and lastly Hip circumference. Three BP recordings were taken. The first record was taken after the participant has rested for 15 minutes with their legs uncrossed. Then, the second and third measurements were taken at three minutes intervals, and average of the last two measurements was used to calculate the mean blood pressure. Height, waist circumference and hip circumference were measured as per the STEPS manual and were recorded to the nearest $0.5 \mathrm{~cm}$. Weight was measured using ordinary bathroom scale and recorded to the nearest 100 grams.

\section{Data Quality Control}

Questionnaires were translated from English into the local language (Amharic) \& vice versa. A pre-test was conducted on $5 \%$ of the sample in "Qitte" town (capital of a district nearby). Data collectors were trained on how to conduct the physical measurements and correct application of the instruments. Instruments were checked for functionality before data collection. Daily supervision was held at all kebeles' by field supervisors and the investigator. Data collectors were enabled to rectify incomplete and inconsistent data by supervisors at the time of data collection. Supervisors used to check all procedures and completeness of formats randomly. The data was entered using a double entry method using EpiData software.

\section{Data Processing and Analysis}

The data was checked for its completeness and consistencies. Then, it was cleaned, coded and entered in to Epi Data version 3.1 and exported into SPSS for Windows version 20.00.

Descriptive and analytic statistics were computed. Binary logistic regression analysis was conducted to identify determinants of modifiable risk factors for CNCDs. Then, to control the effect of possible confounders, multivariable logistic regression was computed with a confidence interval of $95 \%$. P-value $<0.05$ on a binary logistic regression was considered to select candidate variables for multivariable logistic regression analysis as well as to declare statistically significant variables.

\section{Ethical Considerations}

Before the actual data collection, the proposal was presented to Jimma University, and then ethical clearance letter was obtained from Institutional Review Board (IRB) of College of Health Sciences. The participants were well informed about the purposes of the study, and oral consents were obtained accordingly. The participants' rights to refuse or withdraw from participating in the study and confidentiality issues were considered.

\section{Results}

A total of 404 participants were involved in the study with $100 \%$ response rate.

\section{The Socio-Demographic Characteristics}

Among the study participants, 219 (54.2\%) were men and 185 (45.8\%) were women. Nearly half of the study participants, 199(49.3\%), were Orthodox religion followers whereas the dominant ethnic group was Bench 168 (41.6\%). About 178 $(44.1 \%)$ respondents attended primary education or none. Above half, 225 (55.7\%), of the study subjects were married. The main work status of the study participants over the past 12 months had been reported with higher numbers of government employee 167 (41.3\%) and self-employee 141 (34.9\%). The income of about $82 \%$ of the study participants was greater or equal to $\$ 1.25$ /day whereas the rest $18 \%$ earns less than $\$ 1.25$ / day (Table 1).

Table 1: Socio-demographic characteristics of the study participants in Mizan-Aman town, Oct. 2015.

\begin{tabular}{|c|c|c|}
\hline Variables & Men (n=219) No (\%) & Women (n=185) No (\%) \\
\hline \multicolumn{2}{|c|}{ Age } & $86(46.5)$ \\
\hline $25-34$ & $99(45.7)$ & $66(35.7)$ \\
\hline $35-44$ & $66(30.0)$ & \\
\hline
\end{tabular}


Juniper Online Journal of Public Health

\begin{tabular}{|c|c|c|}
\hline $45-54$ & $22(10.0)$ & $22(11.9)$ \\
\hline $55-64$ & $32(14.6)$ & $11(5.9)$ \\
\hline \multicolumn{3}{|c|}{ Educational Status } \\
\hline Primary educ \& less & $114(52.1)$ & $64(34.6)$ \\
\hline Secondary education & $89(40.6)$ & $31(16.8)$ \\
\hline College/University & $16(7.3)$ & $90(48.6)$ \\
\hline \multicolumn{3}{|c|}{ Ethnicity } \\
\hline Bench & $119(54.3)$ & $49(26.5)$ \\
\hline Kaffa & $57(26.0)$ & $83(44.9)$ \\
\hline Amhara & $22(10.0)$ & $27(14.6)$ \\
\hline Others & $21(9.6)$ & $26(14.1)$ \\
\hline \multicolumn{3}{|c|}{ Religion } \\
\hline Orthodox & $112(51.1)$ & $87(47.0)$ \\
\hline Protestant & $90(41.1)$ & $84(45.4)$ \\
\hline Muslim \& others & $17(7.8)$ & $14(7.6)$ \\
\hline \multicolumn{3}{|c|}{ Marital Status } \\
\hline Unmarried & $61(27.9)$ & $43(23.2)$ \\
\hline Married & $125(57.1)$ & $100(54.1)$ \\
\hline Divorced & $22(10.0)$ & $16(8.6)$ \\
\hline Widowed & $11(5.0)$ & $26(14.1)$ \\
\hline \multicolumn{3}{|c|}{ Work Status } \\
\hline Government employee & $77(35.2)$ & $90(48.6)$ \\
\hline NG employee & $16(7.3)$ & $20(10.8)$ \\
\hline Self-employee & $93(42.5)$ & $48(25.9)$ \\
\hline Others & $33(15.0)$ & $27(14.6)$ \\
\hline \multicolumn{3}{|c|}{ Income (USD) } \\
\hline Below 1.25 USD/day & $37(16.9)$ & $36(19.5)$ \\
\hline 1.25 or more USD/day & $182(81.3)$ & $149(80.5)$ \\
\hline
\end{tabular}

\section{The Distribution of Behavioral Risk Factors}

Tobacco Use: The number of current smokers' was 34 (8.4\%). Among the current smokers 28 (82.4\%) smoked manufactured tobacco products whilst 6 (17.6\%) smoked hand-rolled cigarettes. Sixteen (4\%) of the study participants reported someone smoked in their home within the past seven days. Thirty (7.4\%) participants, on the other hand, declared someone smoke at work place in their presence within the past seven days.

Alcohol Consumption: Current alcohol consumers were 145 (35.9\%). Among the current drinkers; 63 (54.8\%) men were heavy drinkers whereas only one woman $(3.3 \%)$ reported heavy drinking. Sixty eight (46.9\%) consume alcohol usually with meals whilst $22(15.2 \%)$ never consume alcohol with meals. Nearly all of alcohol consumer women, 29 (96.7\%), reported usually consumption of alcohol with meals.

Fruit and Vegetable Consumption: The mean numbers of days' fruits and vegetables consumed in a typical week were 4 and 4.75 , respectively. The mean number of fruit servings consumed on a typical day was 4 whilst the same for vegetable servings on a typical day was 3.5. The mean number of combined servings of fruits and vegetables was 7.5. About 94 (23.3\%) reported consumption of less than five servings of fruits and/or vegetables on a typical day.

Physical Activity: Low level of total physical activity $(<600$ MET-minutes/week) was $43(10.6 \%)$ in the study population. 
Majority, 361(89.4\%), had adequate physical activity. Reasons for this may be the involvement of considerable proportion, $302(74.8 \%)$, of the study participants in moderate intensity activities and the fact that about 363 (89.9\%) reported walking at least for 10 minutes per day, but it needs further investigation (Table 2).

Table 2: Frequency distribution of level of total physical activity by sex in Mizan-Aman town, Oct 2015.

\begin{tabular}{|c|c|c|}
\hline Level of Physical Activity & Men (n=219) No (\%) & Women (n=185) No (\%) \\
\hline High ( $\geq 3000$ MET- min/week) & $152(69.4)$ & $98(53.0)$ \\
\hline Moderate (600-2999 MET-min/week) & $43(19.6)$ & 68(36.8) \\
\hline Low (<600MET min/week) & $24(11.0)$ & $19(10.3)$ \\
\hline
\end{tabular}

Khat Chewing: Current khat chewers were 57(14.1\%); among which $44(77.2 \%)$ were men and $13(22.8 \%)$ were women. The frequency of khat chewing practice among current chewers measured as daily, usually and sometimes were $20.7 \%, 36.2 \%$ and $43.1 \%$, respectively.

\section{The Distribution of Biological Risk Factors}

Hypertension: About 49(12.1\%) study participants were hypertensive. Thirty (7.4\%) respondents were receiving antihypertensive drugs at the time of the study. The number of prehypertensive participants was 99 (24.5\%). The mean systolic and diastolic blood pressures were $117(\mathrm{SD} \pm 13) \mathrm{mmHg}$ and 78(SD \pm 7$) \mathrm{mmHg}$, respectively (Table 3).

Table 3: Frequency distribution of BP classification by sex in Mizan-Aman town, Oct 2015.

\begin{tabular}{|c|c|c|}
\hline BP Classification & Men (n=219) No (\%) & Women (n=185) No (\%) \\
\hline Normal (SBP<120 and/or DBP<80) & $141(64.4)$ & $115(62.2)$ \\
\hline Pre-hypertension (SBP 120-139 and/or DBP 80-89) & $55(25.1)$ & $44(23.8)$ \\
\hline Hypertension (SBP>140 or DBP $\geq 90 \mathrm{mmHg})$ & $23(10.5)$ & $26(14.1)$ \\
\hline
\end{tabular}

Overweight/Obesity: The study revealed that 49 (12.1\%) study subjects were overweight (BMI 25-29.9) whereas 16(4.0\%) were found being obese (BMI $\geq 30$ ). The number of overweight women was significantly higher than that of overweight men (67.3\% Vs $32.7 \%)$. The overweight subjects were mainly government employee (34.7\%) and self-employee (65.3\%).
All obese (4.0\%) study subjects were women and government employee; i.e. none men was found obese. Eighty six (21.29\%) women had central obesity (WHR > 0.85); whilst none men was found being at risk for central obesity (WHR $>1.0$ ).

Raised Risk: Above half, 204(50.5\%), of the study population had at least one or more of the key risk factors (Table 4).

Table 4: Combined key risk factors for CNCDs in Mizan-Aman town, Oct 2015.

\begin{tabular}{|c|c|c|c|}
\hline Number of Risk Factors & $\begin{array}{c}\text { Men (n=219) } \\
\text { No (\%) }\end{array}$ & $\begin{array}{c}\text { Women (n=185) } \\
\text { No (\%) }\end{array}$ & $\begin{array}{c}\text { Total (n=404) } \\
\text { No (\%) }\end{array}$ \\
\hline 0 risk factors & $122(55.7)$ & $18(42.2)$ & $187(45.6)$ \\
\hline $1-2$ risk factors & $86(39.3)$ & $6(3.2)$ & $17(4.2)$ \\
\hline
\end{tabular}

\section{Determinants of Modifiable Risk Factors of CNCDs}

The multivariable logistic regression analysis revealed that sex, educational status, marital status, work status and income were positive predictors of behavioral risk factors of CNCDs. The odds of smoking among those who had educational status of primary and below was nearly three times (AOR=2.9, $95 \% \mathrm{CI}=1.37,6.12$ ) higher than that of among secondary and above. It also showed that work status was positive predictor of low servings of fruits and/or vegetables; i.e., the odds of low servings of fruits and/or vegetables among employed study participants was three times more likely $(\mathrm{AOR}=3.03,95 \% \mathrm{CI}=$ $1.69,5.44$ ) as compared to that of unemployed subjects. Besides; the odds of physical inactivity among those who had educational status of secondary and above was five times higher (AOR=5.02, $95 \% \mathrm{CI}=1.40$, 17.95) than among those who had primary education and below (Table 5). 
Table 5: Determinants of behavioral risk factors of CNCDs in Mizan-Aman town, Oct 2015.

\begin{tabular}{|c|c|c|c|c|}
\hline \multirow{2}{*}{\multicolumn{2}{|c|}{ Variables }} & \multicolumn{2}{|c|}{ Hypertension } & \multirow{3}{*}{$\begin{array}{c}\text { Adjusted OR (95\% CI) } \\
2.16(1.13,4.12)^{*}\end{array}$} \\
\hline & & Yes & No & \\
\hline \multirow{2}{*}{ Age } & $25-44$ & 32 & 285 & \\
\hline & $45-64$ & 17 & 70 & 1 \\
\hline \multirow{2}{*}{ Work status } & Employed & 32 & 312 & $3.86(1.97,7.52)^{*}$ \\
\hline & Unemployed & 17 & 43 & 1 \\
\hline \multirow{2}{*}{ Alcohol drinking } & Current drinker & 10 & 135 & $2.39(1.13,5.09)^{*}$ \\
\hline & Not drinker & 39 & 220 & 1 \\
\hline \multirow{2}{*}{$\begin{array}{c}\text { Low servings of fruits \& } \\
\text { Veg }\end{array}$} & Yes & 17 & 77 & 1 \\
\hline & No & 32 & 278 & $2.19(1.12,4.28)^{*}$ \\
\hline \multirow{4}{*}{ Physical inactivity } & Yes & 15 & 28 & $5.60(2.67,11.77)^{*}$ \\
\hline & No & 34 & 327 & 1 \\
\hline & & \multicolumn{2}{|c|}{ Overweight } & \\
\hline & & Yes & No & \\
\hline \multirow{2}{*}{ Sex } & Men & 16 & 203 & 1 \\
\hline & Women & 48 & 137 & $4.89(2.63,9.08)^{*}$ \\
\hline \multirow{2}{*}{ Age } & $25-44$ & 44 & 273 & 1 \\
\hline & $45-64$ & 20 & 67 & $2.31(1.23,4.35)^{*}$ \\
\hline \multirow{2}{*}{ Alcohol drinking } & Current drinker & 35 & 110 & $2.52(1.47,4.40)^{*}$ \\
\hline & Not drinker & 29 & 230 & 1 \\
\hline
\end{tabular}

The analysis also disclosed that sex, age, work status, alcohol drinking, low servings of fruits and/or vegetables and physical inactivity were positive predictors of biological risk factors of CNCDs. The odds of overweight among women was nearly five times $(\mathrm{AOR}=4.89,95 \% \mathrm{CI}=2.63,9.08)$ higher than that of men. The odds of being overweight among current alcohol drinkers was two and half times higher $(\mathrm{AOR}=2.52,95 \% \mathrm{CI}=$
$1.47,4.40$ ) than that of not drinkers. Similarly, the odds of being hypertensive among current alcohol drinkers was more than two times higher $(\mathrm{AOR}=2.39,95 \% \mathrm{CI}=1.13,5.09)$ as compared to that of not drinkers. The odds of hypertension among physically inactive subjects, on the other hand, was nearly six times more likely (AOR=5.60, 95\% CI $=2.67,11.77$ ) as compared to those who had adequate physical activity (Table 6).

Table 6: Determinants of biological risk factors of CNCDs in Mizan-Aman town, Oct 2015.

\begin{tabular}{|c|c|c|c|c|}
\hline \multicolumn{2}{|c|}{ Variables } & \multicolumn{2}{|c|}{ Hypertension } & \multirow{3}{*}{$\begin{array}{c}\text { Adjusted OR (95\% CI) } \\
2.16(1.13,4.12)^{*}\end{array}$} \\
\hline & & & & \\
\hline \multirow{2}{*}{ Age } & $25-44$ & $\begin{array}{l}\text { Yes } \\
32\end{array}$ & $\begin{array}{l}\text { No } \\
285\end{array}$ & \\
\hline & $45-64$ & 17 & 70 & 1 \\
\hline \multirow{2}{*}{ Work status } & Employed & 32 & 312 & $3.86(1.97,7.52)^{*}$ \\
\hline & Unemployed & 17 & 43 & 1 \\
\hline \multirow{2}{*}{ Alcohol drinking } & Current drinker & 10 & 135 & $2.39(1.13,5.09)^{*}$ \\
\hline & Not drinker & 39 & 220 & 1 \\
\hline \multirow{2}{*}{$\begin{array}{c}\text { Low servings of fruits \& } \\
\text { Veg }\end{array}$} & Yes & 17 & 77 & 1 \\
\hline & No & 32 & 278 & $2.19(1.12,4.28)^{*}$ \\
\hline \multirow{2}{*}{ Physical inactivity } & Yes & 15 & 28 & $5.60(2.67,11.77)^{*}$ \\
\hline & No & 34 & 327 & 1 \\
\hline
\end{tabular}


Juniper Online Journal of Public Health

\begin{tabular}{|c|c|c|c|c|}
\hline \multirow{2}{*}{} & & \multicolumn{2}{|c|}{ Overweight } & \multirow{2}{*}{ No } \\
\cline { 2 - 5 } & & Yes & 203 & 1 \\
\hline \multirow{2}{*}{ Sex } & Men & 16 & 137 & $4.89(2.63,9.08)^{*}$ \\
\cline { 2 - 5 } & Women & 48 & 273 & 1 \\
\hline \multirow{2}{*}{ Age } & $25-44$ & 44 & 67 & $2.31(1.23,4.35)^{*}$ \\
\cline { 2 - 5 } & $45-64$ & 20 & 110 & $2.52(1.47,4.40)^{*}$ \\
\hline \multirow{2}{*}{ Alcohol drinking } & Current drinker & 35 & 230 & 1 \\
\hline
\end{tabular}

\section{Discussion}

This study had focused on determining the prevalence and determinants of known behavioral and biological risk factors for CNCDs. The prevalence of current smoking (8.4\%) was significantly lower than the WHO report of 2012 global prevalence [16] and findings of an assessment on cardiovascular risk factors in SSA countries [8]; but higher than findings of a study in Nigeria [10]. This finding was almost consistent with the findings of a study in Kenya [9] and findings of a study on higher education students in Ethiopia [17].

The prevalence of current alcohol consumption (35.9\%) was consistent with the findings of a study in Maharashtra, India [18], and the global prevalence of alcohol consumption; [19] whereas it was significantly higher than the findings of studies in Uganda, Kenya and South West Ethiopia [9,12,11]. Here it's clear that considerable proportion of the population, due to alcohol consumption, is at higher risk of CNCDs; which calls for prompt action. Among current alcohol consumers; the proportion of men $(54.8 \%)$ reported heavy drinking was significantly higher than that of women heavy drinkers $(3.3 \%)$. This is consistent with the findings of studies on CVDs risk factors, and substance use and its association with HBP in Ethiopia [20,21].

About $23.3 \%$ of the population reported consumption of fruits and vegetables below adequate level. This finding is consistent with the findings of a study in South West Ethiopia [11]. The proportion of the population who consumed fruits and vegetables below adequate level in this study was by far lower than the findings of studies in Vietnam, Jordan, Mozambique and Ethiopia [13,20,22,23]. One of the possible reasons for the difference may be the abundant production of fruits and vegetables in the study area; but it needs further investigation for this study does not address such issues.

Low level of total physical activity (< 600 MET-minutes/ week) was $10.6 \%$ in the study population. This finding is significantly lower than the study findings in Kenya, South West Ethiopia and Tanzania $[9,11,24]$. One of the reasons for this may be the fact that majority, $89.4 \%$, of the study population had adequate physical activity. The prevalence of current khat chewing was $14.1 \%$. This study finding was lower than the study findings in South West Ethiopia [11].
The prevalence of hypertension $(12.1 \%)$ was higher than the study findings in south west whilst it was considerably lower than findings of the studies in Kenya, Uganda, Iran and Vietnam $[9,25,13,14]$. One of the reasons, for this particular study, might be the fact that high proportion of the population was physically active and consumed adequate servings of fruits and/or vegetables per day. The prevalence of hypertension in the population was higher among women (53.1\%) as compared to that of among men (46.9\%). This is consistent with the study findings in Ethiopia [11]. The mean systolic and diastolic blood pressures were $117(\mathrm{SD} \pm 13) \mathrm{mmHg}$ and $78(\mathrm{SD} \pm 7) \mathrm{mmHg}$, respectively. This may be due to the fact that majority of the study participants were physically active and exercised adequate consumption of fruits and vegetables. This finding is in line with the study findings in Uganda [25].

The prevalence of overweight (BMI 25-29.9) was 12.1\%, whilst the prevalence of obesity (BMI $\geq 30)$ was $4.0 \%$. These findings were considerably lower than the global prevalence and study findings in Nigeria $(10,26)$. In contrary, the prevalence of overweight was also higher than the findings of some similar studies in Vietnam, Kenya and Ethiopia $[9,13,15]$. The proportion of overweight women was significantly higher than that of overweight men (67.3\% Vs $32.7 \%)$. This is consistent with the study findings in Nigeria and Ethiopia $[10,26]$

The study revealed that sex, age, educational status, marital status, work status and income were positive predictors of risk factors of CNCDs. This is consistent with the study findings in Kenya where sex, age, educational status and work status were found to be positive predictors of risk factors of CNCDs [9]. Educational status showed statistically significant association with physical inactivity and current smoking. This is also in agreement with the study findings in Kenya and Ethiopia [9,27]. The implication of these findings could be when people become educated; they might have better access for health information about the health effects of smoking and physical inactivity from different sources like media, news papers and scientific articles. Work status also showed a significant association with low servings of fruits and vegetables. The implication of this finding could be when people have works with better income; they might have better opportunity to purchase and consume fruits and 
vegetables. Hence, this might help them to eat a recommended amount of fruits and vegetables.

Alcohol consumption and physical inactivity showed a significant association with hypertension. This is consistent with the study findings in Nepal $[28,29]$. This might imply that alcohol drinkers and physically inactive people are at more risk of developing the hypertension.

\section{Conclusion}

The prevalence of alcohol consumption was the highest followed by the prevalence of low servings of fruits and/or vegetables; as compared to other risk factors. Sex, educational status, marital status, work status and income were positive predictors of behavioral risk factors of CNCDs. Sex, age, work status, alcohol drinking, low servings of fruits and/or vegetables and physical inactivity were positive predictors of biological risk factors of CNCDs. Besides, sex was significantly associated with alcohol drinking, khat chewing and overweight. Work status also showed significant associations with low servings of fruits and/ or vegetables, physical inactivity and hypertension. Educational status, on the other hand, was seen to have significant associations with current smoking and physical inactivity.

\section{Recommendation}

This study revealed that about half of the study population possessed at least one or more of the key risk factors of CNCDs. Therefore, Mizan-Aman town health office should plan and implement health education programs on prevention and control of CNCDs. On top of this, Bench-Maji zone health department and Mizan-Aman town health office should design a local media plan to aware the public about CNCDs and their risk factors. Federal Ministry of Health (FMOH) and SNNPRS health bureau in collaboration with other stakeholders should encourage further studies on risk factors of CNCDs. Any interested researcher should conduct further study on the biochemical measurements to have a better picture of the prevalence of the risk factors of CNCDs. It is highly recommended that government should set up a community-based CNCDs risk factors surveillance system in the future.

\section{Acknowledgment}

We would like to express our deepest gratitude and appreciation to Mizan-Aman Health Science College, Bench-Maji zone chief administrative office and Bench Maji zone health department for their material and financial support to undertake the research work. We would also like to extend our thanks to Jimma University, Institutional Review Board of Health Science College, for ethically cleared the research activity. Finally, our great appreciation goes to the data collectors and supervisors who participated in the study.

\section{Refernces}

1. WHO (2012) Global Health Estimates: deaths by cause, age, sex and country.
2. Dalal S, Beunza JJ, Volmink J, Adebamowo C, Bajunirwe F, et al. (2011) Non-communicable diseases in SSA: what we know now. Int J Epidemiol 40: 885-901.

3. De Graft, Aikins A, Unwin N, Agyemang C, Allotey P et al. (2010) Tackling Africa's chronic disease burden from the local to the global. Global Health 6: 5.

4. Maher D, Smeeth L, Sekajugo J (2010) Health transition in Africa: practical policy proposals for primary care. Bull World Health Organ 88: 943-948.

5. (2011) World Health Organization. Non-communicable diseases country profiles, Geneva: WHO.

6. Daar AS, Singer PA, Persad DL, Pramming SK, Matthews DR, et al. (2007) Grand challenges in chronic non-communicable diseases. Nature 450(7169): 494-946.

7. Kebede D (2005) Khat and alcohol use and risky sex behavior among in-school and out-of-school youth in Ethiopia. BMC Public Health 5: 109-114.

8. Belue R, Okoror TA, Iwelunmor J, Taylor KD, Degboe AN, et al. (2008) An overview of cardiovascular risk factor burden in SSA countries : a socio-cultural perspective 12: 2005-2008.

9. Tawa N, Frantz J, Waggie F (2011) Risk factors for chronic non communicable diseases in Mombasa, Kenya: Epidemiological study using WHO step wise approach 19(3): 2005-2008.

10. Sani UM, Wahab KW, Yusuf BO, Gbadamosi M, Johnson OV (2010) Modifiable cardiovascular risk factors among apparently healthy adult Nigerian population - a cross sectional study p. 3(11): 20-23.

11. Alemseged F (2012) Risk factors for CNCDs at gilgel gibe field research center, Southwest Ethiopia: Population based study. Ethiop J Heal scinces 22: 22.

12. Olivia N, Juliet NS, Simon K, Peter W, Nicholas T, et al. (2011) Risk factors for non-communicable diseases in rural Uganda: a pilot surveillance project among diabetes patients at a referral hospital clinic. Pan Afr Med J 8688: 1-11.

13. Pham LH, Au TB, Blizzard L, Truong NB, Schmidt MD, et al. (2009) Prevalence of risk factors for NCDs in the Mekong Delta, Vietnam: results from a STEPS survey 8: 1-8.

14. Press D (2011) Risk factor investigation for cardiovascular health through WHO STEPS approach in Ardabil, Iran. Vasc Health Risk Manag pp. 417-419.

15. (2015) WHO. NCDs risk factors. Obesity. Global Health Observatory (GHO) data.

16. (2013) WHO. Tobacco control: prevalence of tobacco use: Global Health Observatory (GHO) data.

17. Seblewengel Lemma (2007) Assessment of Risk Factors for Selected Chronic Diseases among Higher Education Students in Addis Ababa.

18. Bhardwaj SD, Shewte MK, Bhatkule PR, Khadse JR (2012) Prevalence of risk factors for NCDs in a rural area of nagpur district, maharashtra - A WHO STEP wise approach 3(1): 1413-1418.

19. (2015) WHO. The Global Information System on Alcohol and Health, Management of substance abuse, facts and figures.

20. Tesfaye F (2008) Epidemiology of CVD Risk Factors in Ethiopia: The rural-urban gradient.

21. Tesfaye F, Byass P, Berhane Y, Bonita R (2008) Association of smoking and khat (catha edulis forsk) use with high blood pressure among adults in Addis Ababa. Public Heal Res Pract policy 5(3): 89.

22. Al-nsour M, Zindah M, Belbeisi A, Hadaddin R (2012) Prevalence of Selected CNCDs Risk Factors in Jordan: Results of the 2007 Jordan Behavioral Risk Factor Surveillance Survey 9(1): 1-9. 
23. Padrão P, Laszczynska O, Silva-Matos C, Damasceno A, Lunet N (2012) Low fruit and vegetable consumption in Mozambique: results from a WHO step wise approach to chronic disease risk factor surveillance. $\mathrm{Br}$ J Nutr 107: 428-435.

24. Alfa M (2012) Physical activity and CVDs risk factors among young and middle- aged men in urban Mwanza, Tanzania. Pan Afr Med J 8688: 1-9.

25. S VZ, Lj VDM, Sa DA (2010) A risk-factor profile for chronic lifestyle diseases in three rural Free State towns 52(1): 72-76.

26. (2015) WHO: NCDs risk factors. Obesity: Global Health Observatory (GHO) data: WHO.

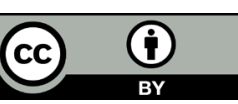

This work is licensed under Creative Commons Attribution 4.0 License

DOI: 10.19080/JOJPH.2018.03.555622
27. Kebede Y (2002) Cigarette smoking and Khat chewing among college students in North West Ethiopia. 2001. 6-15. Ethiop J Health Dev 16(1): 9-17

28. Awoke (2012) Prevalence and associated factors of hypertension among adults in Gondar, Northwest Ethiopia: a community based cross-sectional study. BMC Cardiovascular Disorders 12: 113.

29. Chataut J, Adhikari RK, Sinha NP (2011) Prevalence and risk factors for hypertension in Adults living in Central Development Region of Nepal. Kathmandu univ med J 33(1): 13-18.

Your next submission with Juniper Publishers
will reach you the below assets
- Quality Editorial service
- Swift Peer Review
- Reprints availability
- E-prints Service
- Manuscript Podcast for convenient understanding
- Global attainment for your research
- Manuscript accessibility in different formats
( Pdf, E-pub, Full Text, Audio)
- Unceasing customer service
Track the below URL for one-step submission
https://juniperpublishers.com/online-submission.php

